\title{
Mutation of V896M in cardiac myosin binding protein-c gene in two Chinese families with hypertrophic cardiomyopathy
}

\author{
AI-LING WANG ${ }^{1}$, DE-HUA KONG ${ }^{1}$, DUO-XUE CHEN ${ }^{1}$, JUN WAN $^{1}$ and YUAN-XUN YU ${ }^{2}$ \\ ${ }^{1}$ Department of Cardiogy, The First Affiliated Hospital of Anhui Medical University, Hefei 230022; \\ ${ }^{2}$ The Center of Medical Genetics of Anhui Province, Hefei 230031, P.R. China
}

Received April 7, 2010; Accepted July 12, 2010

DOI: $10.3892 / \mathrm{mmr} .2010 .333$

\begin{abstract}
To investigate the genotype-phenotype correlation in Chinese familial and sporadic hypertrophic cardiomyopathy, specific exons of the myosin binding protein-c gene (MYBPC3) were screened in six families with hypertrophic cardiomyopathy (HCM; FHCM) and in 20 patients with sporadic HCM (SHCM) from the Anhui Province region of China. The V896M mutation was detected for the first time in China in two families with FHCM. The mutation was not found in 100 healthy control subjects. No mutations of $M Y B P C 3$ were detected in any of the SHCM patients. In contrast to previous reports, the V896M mutation may be a disease-causing mutation in China, and exon 27 of $M Y B P C 3$ may be a mutational hotspot in FHCM patients. However, mutations of $M Y B P C 3$ were not prevalent among SHCM patients.
\end{abstract}

\section{Introduction}

Hypertrophic cardiomyopathy (HCM) is the most common genetic cardiac disease, and is characterized by a very heterogeneous morphologic expression and clinical course $(1,2)$. With an estimated prevalence in the general population of approximately 1:500, there are potentially over one million patients with HCM in China alone (3). Genetic screening is a necessary tool for a definite diagnosis of HCM, particularly in subjects with atypical or borderline phenotypic expression (4). Several sarcomeric and non-sarcomeric protein genes have been associated with the disease, and novel culprit genes are being described every year. Thus, comprehensive molecular screening for HCM represents a technical and economic challenge and is hardly feasible in China. The two most common sarcomeric genes involved in HCM are $\alpha$-myosin heavy chain (MYH7) and cardiac myosin binding protein-c

Correspondence to: Dr Ailing Wang, Department of Cardiogy, The First Affiliated Hospital of Anhui Medical University, Hefei 230022, P.R. China

E-mail:wal@ah.edu.cn

Key words: mutation, V986M, gene, hypertrophic cardiomyopathy
(MYBPC3). These genes account for a proportion of diseaseassociated mutations that was consistently high in Europe (5), despite wide fluctuations attributable to the different genetic backgrounds of the study subjects. Based on the screening of MYH7 in six families one year ago, we determined that the comprehensive screening of $M Y B P C 3$ may provide a favorable yield of genotyped index cases. The present study was undertaken in the same six unrelated Chinese families with HCM (FHCM) and in 20 patients with sporadic HCM (SHCM) at the Department of Cardiology of The First Affiliated Hospital of Anhui Medical University.

\section{Materials and methods}

Clinical materials. A total of 20 patients in six unrelated families ( 8 males and 12 females; age range 17-70 years) and 20 SHCM patients were identified through the patient register of the Department of Cardiology of our hospital and evaluated. The main clinicopathologic findings of these patients are summarized in Table I. The diagnosis of HCM was based on the presence of a maximal left ventricular wall thickness of at least $13 \mathrm{~mm}$, determined by two-dimensional echocardiography. The absence of other causes of ventricular hypertrophy, such as hypertension, aortic stenosis, physical exercise or the use of some drugs, was confirmed in each patient. Electrocardiographic and echocardiographic examinations were also performed in the six families. All individuals gave their informed consent for participation. The study was approved by the Ethical Committee of the hospital. To confirm the absence of any new putative mutation in the MYBPC3 gene among the healthy individuals, a total of 100 controls were genotyped. The controls did not have a history of cardiovascular disease, including HCM.

Genetic studies. MYBPC3 sequencing of genomic DNA was prepared from peripheral blood leukocytes using a salting-out procedure. Exons 13, 15-16, 26 and 27 of the MYBPC3 gene, as well as the corresponding exon-intron boundaries (gi:89161188) (Table II), were sequenced in all probands of the six families and 20 SHCM patients. PCR reactions were performed in a GeneAmp PCR system (Hema-240; PCR Zhuhai Biotechnology Group, P.R. China). Each reaction included 1,000 ng of genomic DNA, 7.5 pmol of each primer, $500 \mu \mathrm{mol}$ of dNTP, $2.5 \mu \mathrm{l} 10 \mathrm{X}$ buffer and 2.0 units Taq DNA 
Table I. Main characteristics of the five patients with HCM in the two families showing the V896M mutation.

\begin{tabular}{|c|c|c|c|c|c|c|c|c|c|c|}
\hline \multirow[b]{2}{*}{ Subjects } & \multirow[b]{2}{*}{ Gender/age } & \multirow[b]{2}{*}{ Angina } & \multirow[b]{2}{*}{ Syncope } & \multirow[b]{2}{*}{ NYHA } & \multicolumn{2}{|c|}{ ECG } & \multicolumn{4}{|c|}{$\mathrm{UCG}(\mathrm{mm})$} \\
\hline & & & & & $\mathrm{LVH} / \mathrm{ST}$ & $\mathrm{Q} / \mathrm{BBB}$ & IVS/PW & LVDD & LAD & $\mathrm{EF}(\%)$ \\
\hline DI:1 & $\mathrm{F} / 63$ & + & - & III & + & + & $15 / 10$ & 58 & 44 & 48 \\
\hline DII: 1 & $\mathrm{M} / 40$ & - & - & II & - & - & $14 / 11$ & 52 & 56 & 68 \\
\hline EI:2 & $\mathrm{M} / 69$ & - & - & IV & + & - & $19 / 11$ & 65 & 58 & 45 \\
\hline EII:1 & $\mathrm{F} / 46$ & - & - & III & + & + & $14 / 12$ & 57 & 45 & 50 \\
\hline EII:3 & $F / 43$ & - & - & II & - & - & $15 / 11$ & 53 & 57 & 69 \\
\hline
\end{tabular}

ECG, electrocardiography; M, male; F, female; LVH, left ventricular hypertrophy; IVS, interventricular septal thickness; PW, posterior left ventricular wall; LVDD, LV end-diastolic dimension; EF, ejection fraction; LAD, left atrial diameter.

Table II. Primers and PCR conditions for analysis of the MYBPC3 gene.

\begin{tabular}{|c|c|c|c|}
\hline \multirow[t]{2}{*}{ Exon } & \multicolumn{2}{|c|}{ Primers } & \multirow[t]{2}{*}{ Annealing $\left({ }^{\circ} \mathrm{C}\right)$} \\
\hline & Forward & Reverse & \\
\hline Exon 13 & $5^{\prime}$ tccecageccetcttca3' & $5^{\prime}$ gccggactccgctcttt $3^{\prime}$ & 62 \\
\hline Exon $15+16$ & $5^{\prime}$ ctctccttttgtctcgggct $3^{\prime}$ & 5'gggtgagcatgagggttggc $3^{\prime}$ & 62 \\
\hline Exon 26 & 5'aacagatccgagggaaggtgg $3^{\prime}$ & $5^{\prime}$ tttttaactggggagggggc $3^{\prime}$ & 59.5 \\
\hline Exon 27 & $5^{\prime}$ ggaagtgccectatgt $3^{\prime}$ & 5'tcgcactgctcaaagaag3' & 62 \\
\hline
\end{tabular}

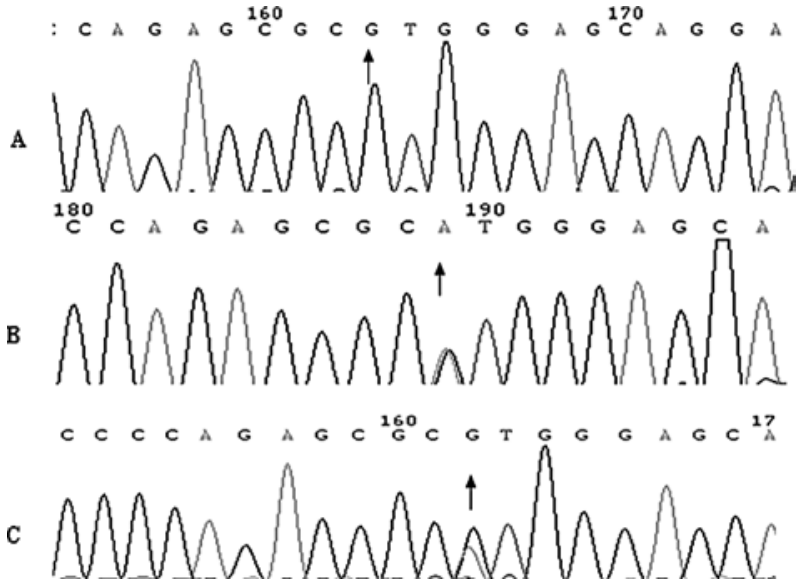

Figure 1. Sequencing analysis of exon 27 of the $M Y B P C 3$ gene. (A) wildtype; (B) family D; (C) family E. Partial sequence of exon 27 of $M Y B P C 3$ showing the heterozygous $\mathrm{GTG} \rightarrow(\mathrm{G} / \mathrm{A})$ TG substitution at position $n t 16750$ (indicated by the arrow).

polymerase (Sangon Biotechnology, P.R. China). The PCR conditions for the cardiac $M Y B P C 3$ gene were denaturing at $94^{\circ} \mathrm{C}$ for $4 \mathrm{~min}$, followed by 32 cycles of denaturing at $94^{\circ} \mathrm{C}$ for $40 \mathrm{sec}$, annealing at $59.5-62^{\circ} \mathrm{C}$ for $40 \mathrm{sec}$ and extension at $72^{\circ} \mathrm{C}$ for $90 \mathrm{sec}$, with a final extension at $72^{\circ} \mathrm{C}$ for $10 \mathrm{~min}$. Genomic DNA was PCR-amplified with the primer pairs and annealing temperatures summarized in Table II. Each PCR product was analyzed on an ABI PRISM 3730XL automated sequencer (Perkin-Elmer Applied Biosystems, USA)

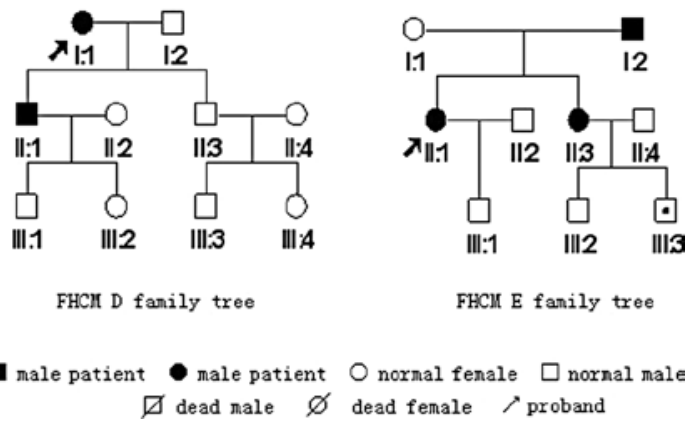

Figure 2. Pedigrees of two of the six families, showing the V896M mutation.

according to dideoxy chain termination reaction sequencing reactions.

\section{Results}

Identification of the V896M-MYBPC3 missense mutation. A $16750 \mathrm{G} \rightarrow \mathrm{G} / \mathrm{A}$ mutation at exon 27 of the $M Y B P C 3$ gene was detected in two probands (families D and E) among the six families, resulting in the replacement of a valine by methionine residue at amino acid 896 (gi:148596956) (Fig. 1). None of the 100 control subjects had the mutation. We then screened exon 27 of the MYBPC 3 gene in other members of the same two families. The results showed that the mutation co-segregated with the disease (Fig. 2, Table III). Mutations of $M Y B P C 3$ were not detected in any of the SHCM patients. 
Table III. Variants in the MYBPC3 and $M Y H 7$ genes in six pedigrees with HCM and 20 SHCM patients.

\begin{tabular}{|c|c|c|c|c|c|}
\hline Family & $\begin{array}{l}\text { Nucleotide } \\
\text { change }\end{array}$ & $\begin{array}{l}\text { Predicted change } \\
\text { in protein }\end{array}$ & $\begin{array}{l}\text { Previous } \\
\text { publication }\end{array}$ & $\begin{array}{l}\text { No. of probands }(\mathrm{n}=5) / \\
\text { relatives with variant }\end{array}$ & $\begin{array}{c}\text { No. of controls } \\
(n=80) \text { with variant }\end{array}$ \\
\hline \multicolumn{6}{|l|}{ A } \\
\hline & $\begin{array}{c}\text { MYH7 Exon } 18^{\mathrm{a}} \\
(\mathrm{nt} 12601: \mathrm{G} \rightarrow \mathrm{A} / \mathrm{G})\end{array}$ & Arg663His & Yes & $1 / 3$ & 0 \\
\hline \multicolumn{6}{|l|}{ B } \\
\hline & $\begin{array}{c}\text { MYH7 Intron } 18 \\
\text { (nt9088: deletion A) }\end{array}$ & No & No & $1 / 2$ & 3 \\
\hline & $\begin{array}{c}\text { MYH7 Exon } 20^{\mathrm{a}} \\
(\mathrm{nt} 13619: \mathrm{C} \rightarrow \mathrm{C} / \mathrm{G})\end{array}$ & Arg723Gly & Yes & $1 / 5$ & 0 \\
\hline \multicolumn{6}{|l|}{$\mathrm{C}$} \\
\hline & $\begin{array}{l}\text { МYH7 Intron } 18 \\
(\mathrm{nt} 9085: \mathrm{G} \rightarrow \mathrm{A} / \mathrm{G})\end{array}$ & No & No & $1 / 2$ & 1 \\
\hline & $\begin{array}{l}\text { MYH7 Exon } 20^{\mathrm{a}} \\
(\mathrm{nt13659:} \mathrm{T} \rightarrow \mathrm{C} / \mathrm{T})\end{array}$ & Ile736Thr & Yes & $1 / 3$ & 0 \\
\hline \multicolumn{6}{|l|}{$\mathrm{D}$} \\
\hline & $\begin{array}{c}\text { МYВРС } 3 \text { Intron } 13 \\
(\text { nt6628: } \mathrm{G} \rightarrow \mathrm{G} / \mathrm{A})\end{array}$ & No & No & $1 / 2$ & 2 \\
\hline & $\begin{array}{l}\text { MYBPC3 Exon } 27 \\
(\mathrm{nt} 16750: \mathrm{G} \rightarrow \mathrm{G} / \mathrm{A})\end{array}$ & Val896Met & Yes & $1 / 2$ & 0 \\
\hline & $\begin{array}{c}\text { MYBPC3 Intron } 26 \\
(\mathrm{nt} 16647: \mathrm{C} \rightarrow \mathrm{C} / \mathrm{T})\end{array}$ & No & No & $1 / 2$ & 1 \\
\hline \multicolumn{6}{|l|}{$\mathrm{E}$} \\
\hline & $\begin{array}{l}\text { МYBPC3 Exon } 27 \\
(\mathrm{nt} 16750: \mathrm{G} \rightarrow \mathrm{G} / \mathrm{A})\end{array}$ & Val896Met & Yes & $1 / 4$ & 0 \\
\hline & $\begin{array}{c}\text { MYBPC3 Intron } 27 \\
(\mathrm{nt} 16813: \mathrm{C} \rightarrow \mathrm{C} / \mathrm{T})\end{array}$ & No & No & $1 / 4$ & 1 \\
\hline & $\begin{array}{c}\text { МYВРC3 Intron } 15 \\
(\mathrm{nt} 9444: \mathrm{G} \rightarrow \mathrm{G} / \mathrm{T})\end{array}$ & No & No & $1 / 3$ & 4 \\
\hline \multicolumn{6}{|l|}{$\mathrm{S} 1$} \\
\hline & 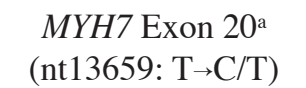 & Ile736Thr & Yes & $1 / 1$ & 0 \\
\hline
\end{tabular}

S1, first sporadic patient; apreviously reported.

Genetic and clinical features. Two pedigrees (families D and E) were selected for genetic study. All affected members presented typical clinical features of the disorder as assessed by physical examination, electrocardiography, two-dimensional echocardiography and Doppler echocardiography. The disease was inherited as an autosomal dominant trait in all cases, as documented by the patient history or clinical evaluation of the relatives. All families were unrelated and of Chinese descent.

In family $\mathrm{D}$, two of the ten members were confirmed to carry the mutated gene. The proband (DI:1) was a 63-year-old man who presented with occasional symptoms of angina. Electrocardiography (ECG) showed left ventricular hypertrophy with left bundle branch block. Echocardiography revealed a ventricular septum thickness of $15 \mathrm{~mm}$ and an ejection fraction (EF) of $48 \%$. His son (DII:1) was 40 years of age, and was diagnosed with HCM 2 years prior due to chest stress. Echocardiography showed an interventricular septum thickness of $14 \mathrm{~mm}$ and posterior wall thickness of $11 \mathrm{~mm}$.
The dimension of the left atrium was $56 \mathrm{~mm}$ while that of the left ventricular diastolic was $52 \mathrm{~mm}$. The EF of $68 \%$.

In family E, the V896M mutation of the MYBPC3 gene was detected in four cases. Three members were diagnosed with HCM. The proband (EII:1), a 46-year-old woman, was diagnosed with HCM due to exertional chest stress 4 years prior. The father of proband was a 69-year-old man with a New York Heart Association functional class (NYHA FC) of IV who presented with frequent symptoms of chest stress. Echocardiography showed an interventricular septum thickness of $19 \mathrm{~mm}$ and posterior wall thickness of $11 \mathrm{~mm}$. The dimension of the left atrium was $58 \mathrm{~mm}$, while that of the left ventricular diastolic was $65 \mathrm{~mm}$. The EF was $45 \%$. The sister of the proband (EII:3) was 43 years of age, and was diagnosed with HCM one year prior during a health examination. Finally, EIII:3 was a 15 -year-old boy determined to carry the V896M mutation, and was confirmed to be healthy through electrocardiographic and echocardiographic examination. 
None of the patients were found to have left ventricular outflow obstruction, as determined by echocardiography, and none of all patients succumbed suddenly to the diease among the two families.

\section{Discussion}

HCM is generally considered to be a strictly autosomal dominant inherited disease, and manifests as left ventricular or interventricular septal asymmetrical hypertrophy. It exhibits variability in its phenotypes, wth clinical manifestations including dizziness, dyspnoea, syncope, angina, serious heart failure, and even sudden death (1). However, symptoms may also be absent, non-specific or late in onset. HCM is largely due to mutations in the genes encoding proteins of the sarcomere. Therefore, it is also called 'sarcomere disease' (6).

The sarcomere complex is composed of thick and thin filaments, and plays a role in the contraction, construction and regulation of human myocardium filaments. MyBPC is a sarcomeric protein associated with the thick filament of striated muscle. It is located in the cross-bridge-containing A-band of the sarcomere in a structurally regular pattern of seven to nine (7). The core structure of MyBPC comprises seven class I immunoglobulin domains and three fibronectin type III (FnIII) domains, numbered from the N-terminus as domains 1-10 (C1-C10) in skeletal muscle. MyBPC has been assigned roles in both the structural assembly and stability of the sarcomere, as well as in the modulation of contraction.

The V896M mutation is located on the field of C7, while domains $\mathrm{C} 7-\mathrm{C} 10$ belong to the $\mathrm{C}$-terminal part of the protein and have a high affinity for the light meromyosin (LMM) portion of myosin and for titin, the structural 'ruler' of the sarcomere. The C-terminal domain, C10, binds to four molecules of LMM via positively-charged amino acids present on its surface (8). However, even though this domain is essential, it is not sufficient for maximal binding to myosin. The three adjacent domains (C7-C9) maximise the affinity of this binding and ensure correct incorporation into the A-band (9).

The V896M mutation was first reported in two South African subpopulations by Moolman-Smook et al (10). A subsequent study by Richard et al (11) showed that the presence of a heterozygous MYBPC3 variant (V896M) contributed to the phenotype severity, and was associated with early hypertrophy when present together with a heterozygous A355T MYH7 mutation. The authors suggested that the V896M variant acts as a modifier polymorphism on the expression of the phenotype.

While a previous study identified the V896M variant in $5 / 111$ control individuals in (12), it was not found among the healthy controls in our study, and the mutation and the disease showed co-separation. It may therefore be a disease-causing mutation in China.

In the two families with the V896M mutation discussed here, the V896M variant of $M Y B P C 3$ was detected in six cases. Five of six family members were diagnosed as having HCM. Only one was confirmed to be a healthy carrier through electrocardiographic and echocardiographic examinations. However, this one (EIII:3) is a 15-year-old boy, and studies have shown that patients with $M Y B P C 3$ mutations usually have a delayed age of onset (13). Long-term follow-up is therefore essential in this patient.
The penetrance in our study was calculated to be $83 \%(5 / 6$ carriers). There were no obstructions in the left ventricular outflow tract in any of the patients, as determined by echocardiographic examination, and none of the patients in the two pedigrees succumbed suddenly to the disease. The carriers who were over 38 years of age had a normal left ventricular dimension and EF, but presented ventricular wall hypertrophy. Most of the 60-year-old carriers presented heart failure and a gradual decrease in the EF. Taken together, the results suggest that the phenotype becomes more malignant with increasing age. Thus, in the present study the V896M mutation was found to exhibit similar features to those reported by Richard et al (13), including the delayed onset of clinical symptoms, slow development and a benign phenotype.

We previously reported three mutations (Family A, Arg663His of exon 18; Family B, Arg 723Gly of exon 20; Family C, Ile736Thr of exon 20; and Ile736Thr of exon 20 in 1 of 20 SHCM patients) of the $M Y H 7$ gene in the same six families and among 20 SHCM patients (Table III) (14). Here, we report a mutation in the $M Y B P C 3$ gene in two of the same six families with HCM. In five of the six families, mutations in the $M Y B P C 3$ and $M Y H 7$ genes were detected. However, only 1 SHCM patient was found to have a Ile736Thr mutation of exon 20 in the $M Y H 7$ gene. This indicates that mutations of the $M Y B P C 3$ and $M Y H 7$ genes frequently occur among FHCM patients, but not among SHCM patients, in China.

In conclusion, we showed a missense mutation, V896M, in two Chinese families with a benign phenotype of HCM with mild clinical symptoms. $M Y B P C 3$ as well as $M Y H 7$ may be the dominant disease-causing genes in Chinese familial HCM patients, while the mutation rate of the $M Y B P C 3$ and $M Y H 7$ genes is significantly lower among sporadic HCM patients. Exon 27 of the $M Y B P C 3$ gene may be a mutational hotspot among Chinese FHCM patients.

\section{Acknowledgements}

This study was supported by the Key Research Project of the Natural Science Foundation of Anhui Provincial Universities (No. KJ2008A156). We would like to thank the staff at the Center of Medical Genetics of Anhui Province for their help with the study.

\section{References}

1. Maron BJ: Hypertrophic cardiomyopathy. A systematic review. JAMA 287: 1308-1320, 2002.

2. Olivotto I and Cecchi F: The epidemiologic evolution and present perception of hypertrophic cardiomyopathy. Ital Heart J 4: 596-601, 2003.

3. Zou Y, Song L, Wang Z, et al: Prevalence of idiopathic hypertrophic cardiomyopathy in china: a population-based echocardiographic analysis of 8080 adults. Am J Med 116: 14-18, 2004.

4. Maron BJ, McKenna WJ, Danielson GK, et al: A report of the American College of Cardiology foundation task force on clinical expert consensus documents and the European Society of Cardiology committee for practice guidelines. Eur Heart J 24: 1965-1991, 2003.

5. Girolami F, Olivotto I, Passerini I, et al: A molecular screening strategy based on $\beta$-myosin heavy chain, cardiac myosin binding protein $\mathrm{C}$ and troponin $\mathrm{T}$ genes in Italian patients with hypertrophic cardiomyopathy. J Cardiovasc Med 7: 601-607, 2006.

6. Watkins H: Hypertrophic cardiomyopathy: from molecular and genetic mechanisms to clinical management. Eur Heart J (Suppl 3): L43-L50, 2001. 
7. Flashman E, Redwood C, Moolman-Smook J, et al: Cardiac myosin binding protein $\mathrm{C}$ : its role in physiology and disease. Circ Res 94: 1279-1289, 2004.

8. Miyamoto CA, Fischman DA and Reinach FC: The interface between MyBP-C and myosin: site-directed mutagenesis of the CX myosin-binding domain of MyBP-C. J Muscle Res Cell Motil 20: 703-715, 1999.

9. Welikson RE and Fischman DA: The C-terminal IgI domains of myosin-binding proteins $\mathrm{C}$ and $\mathrm{H}$ (MyBP-C and $\mathrm{MyBP}-\mathrm{H})$ are both necessary and sufficient for the intracellular crosslinking of sarcomeric myosin in transfected non-muscle cells. J Cell Sci 115: 3517-3526, 2002.

10. Moolman-Smook JC, De Lange WJ, Bruwer ECD, et al: The origins of hypertrophic cardiomyopathy causing mutations in two South African subpopulations: a unique profile of both independent and founder events. Am J Hum Genet 65: 1308-1320, 1999.
11. Richard P, Charron P, Carrier L, et al: Hypertrophic cardiomyopathy: distribution of disease genes, spectrum of mutations and implications for molecular diagnosis strategy. Circulation 107: 2227-2232, 2003

12. Jääskeläinen $P$, Kuusisto $\mathrm{J}$, Miettinen $\mathrm{R}$, et al: Mutations in the cardiac myosin-binding protein $\mathrm{C}$ gene are the predominant cause of familial hypertrophic cardiomyopathy in eastern Finland. J Mol Med 80: 412-422, 2002.

13. Richard P, Villard E, Charron P, et al: The genetic bases of cardiomyopathies. J Am Coll Cardiol 48: A79-A89, 2006

14. Feng J, Wang AL, Cheng ZP, et al: Analysis of 18 and 20 exon of MYH7 gene between patients with sporadic and familial hypertrophic cardiomyopathy in Anhui. Acta Universitaties Medicinalis Anhui (in Chinese with an English abstract) 42: 550-553, 2007. 